\title{
Prolactin modulates the naive $B$ cell repertoire
}

\author{
Elena Peeva, ${ }^{1,2}$ Daniel Michael, ${ }^{1}$ James Cleary, ${ }^{1}$ Jeffrey Rice, ${ }^{1}$ Xian Chen, ${ }^{1}$ \\ and Betty Diamond ${ }^{1,2}$
}

${ }^{1}$ Department of Microbiology and Immunology, and

${ }^{2}$ Department of Medicine, Albert Einstein College of Medicine, Bronx, New York, USA

Prolactin is a peptide hormone produced by the anterior pituitary gland that is critical in lactation. Prolactin can also be produced by lymphocytes, and both B and T cells express prolactin receptors. These findings have suggested that prolactin has immunomodulatory functions. Studies in spontaneously autoimmune hosts have demonstrated a role for prolactin in augmenting autoreactivity. We chose to analyze prolactin effects on anti-DNA B cells in nonspontaneously autoimmune female $\mathrm{BALB} / \mathrm{c}$ mice transgenic for the heavy chain of an anti-DNA antibody. Treatment with prolactin for 4 weeks induced a lupus-like phenotype with an increased number of transgene-expressing B cells, elevated serum anti-DNA antibody titers, and glomerular immunoglobulin deposits. Prolactin caused a decrease in the population of transitional B cells and an increase in mature follicular and marginal zone B cells. The DNA-reactive B cells had a follicular cell phenotype. AntiDNA hybridomas demonstrated that prolactin alters selection of the naive $B$ cell repertoire. The expansion and activation of anti-DNA B cells in prolactin-treated R4A- $\gamma 2 \mathrm{~b}$ BALB/c mice was dependent on the presence of $\mathrm{CD}^{+} \mathrm{T}$ cells. Finally, treatment with prolactin was unable to break tolerance in $\mathrm{R} 4 \mathrm{~A}-\gamma 2 \mathrm{~b}$ transgenic $\mathrm{C} 57 \mathrm{Bl} / 6$ mice, suggesting that responsiveness of the immune system to prolactin is genetically determined.

J. Clin. Invest. 111:275-283 (2003). doi:10.1172/JCI200316530.

\section{Introduction}

Systemic lupus erythematosus (SLE) is a chronic inflammatory disease characterized by the production of autoantibodies directed toward a variety of nuclear antigens. The incidence of SLE is much higher in women than men, with a female to male ratio of 10:1 (1). This preponderance of SLE in women is thought to be mediated, in part, through the female sex hormones, estrogen and prolactin. The effects of these hormones at the cellular and molecular level are not well delineated. It is known that estrogen has immunostimulatory properties and that it stimulates prolactin secretion (2). It has also been shown that estrogen can exacerbate disease in spontaneous murine models of SLE only when prolactin is also present (3). We have recently demonstrated that the effect of estrogen on autoreactive B cells in a nonspontaneously autoimmune mouse model can be partially blocked by bromocriptine, an inhibitor of prolactin secretion (4). Studies in male and female NZB/W F1 lupus-prone mice demonstrated that hyperprolactinemia induced by transplantation of

Received for publication July 29, 2002, and accepted in revised form November 26, 2002.

Address correspondence to: Betty Diamond, Department of Microbiology and Immunology, Albert Einstein College of Medicine, 1300 Morris Park Avenue, Bronx, New York 10461, USA. Phone: (718) 430-4081; Fax: (718) 430-8711;

E-mail: diamond@aecom.yu.edu.

Conflict of interest: The authors have declared that no conflict of interest exists.

Nonstandard abbreviations used: systemic lupus erythematosus (SLE); 2 amino 2 methyl propanol (AMP); double-stranded (ds); nanogram (ng); transitional type 1 (T1); B cell receptor (BCR). pituitary glands leads to disease exacerbation and early mortality $(5,6)$, whereas bromocriptine treatment improves survival (7).

Prolactin is a peptide hormone produced by the anterior pituitary gland that affects mammary growth and development. Over the past decade, it has been determined that prolactin can be produced at extrapituitary sites, including by lymphocytes $(8,9)$. It remains unclear whether the amount of prolactin secreted by lymphocytes is sufficient to affect the prolactin level in the serum. However, in a patient with acute myeloid leukemia, the leukemic cells secreted sufficient prolactin to cause hyperprolactinemia (10). Receptors for prolactin have been found on monocytes and B and T lymphocytes (11-17). Thus, prolactin can function in a paracrine and autocrine as well as an endocrine fashion.

The effects of prolactin on T cells have been studied more extensively than its effects on B cells. Prolactin has been shown to enhance the release of thymocytes from lymphoepithelial complexes in the thymus (18), to act as growth factors for T cells (19), to cause preferential development of $\mathrm{CD} 4^{+} \mathrm{T}$ cells (20), and to promote a Th1 response (21). Mouse helper $\mathrm{T}$ cell clones require prolactin as a cofactor for IL-2-driven lymphoproliferation (22), and anti-prolactin antibodies can inhibit $\mathrm{T}$ lymphocyte responses to mitogens (23).

Elevated prolactin levels have been found in $15-25 \%$ of patients with SLE (24-30). Furthermore, an association has been reported between hyperprolactinemia and anti-DNA reactivity in women less than 50 years of age (30). Some hyperprolactinemic 
patients have prolactinomas (31) or secondary causes of hyperprolactinemia such as hypothyroidism, chronic renal failure, or medication-induced hyperprolactinemia $(32,33)$, but in most patients with SLE, the cause of the increased prolactin levels cannot be found.

Although attempts to correlate prolactin levels with either global lupus activity (34-37) or specific organ involvement (38-40) have yielded varying results, it has been demonstrated that both nonstimulated and mitogen-stimulated lymphocytes from patients with lupus secrete more prolactin than control lymphocytes $(41,42)$. A single nucleotide polymorphism in the upstream promoter of prolactin affects prolactin transcription in lymphocytes; this polymorphism has been shown to associate with SLE in a small cohort of patients (43). It has also been speculated that alterations in cyclic 2 amino 2 methyl propanol (AMP) response-element binding family proteins might be involved in the prolactin upregulation in the lymphocytes of patients with lupus (22). Small clinical trials of bromocriptine, a drug that blocks prolactin secretion by the anterior pituitary, have suggested a beneficial effect in patients with SLE who have mild and moderate disease activity $(44,45)$.

Our laboratory has been studying BALB/c mice transgenic for the $\gamma 2 \mathrm{~b}$ heavy chain of the R4A anti-double-stranded (ds) DNA antibody (46). In these mice, the R4A- $\gamma 2 \mathrm{~b}$ heavy chain can associate with the endogenous light chain repertoire, creating a variety of transgene-encoded antibodies; some of these bind DNA, whereas others do not. Three distinct populations of anti-dsDNA B cells have been identified (47-50). The first is an ignorant or indifferent resting B cell population that is not regulated and produces nonpathogenic, low-affinity antidsDNA antibodies (47). The second is an anergic population that produces high-affinity anti-dsDNA antibodies that acquire a high affinity for DNA by somatic mutation $(48,49)$. The third is a deleted population of naive $B$ cells in which unmutated germline immunoglobulin genes encode high-affinity antidsDNA antibodies. These deleted B cells are easily detectable in R4A- $\gamma 2 \mathrm{~b} / b c l-2$ double-transgenic mice and in R4A- $\gamma 2 \mathrm{~b} \mathrm{NZB/W} \mathrm{F1} \mathrm{mice} \mathrm{(50).}$

In this study, we demonstrate that increased prolactin breaks B cell tolerance in R4A- $\gamma 2 \mathrm{~b} B A L B / c$ mice. Prolactin caused a lupus-like phenotype, characterized by an expansion of the transgene-expressing B cell population, a significant elevation in serum titers of anti-DNA antibody, and $\operatorname{IgG}$ deposits in the glomeruli. The impact of prolactin on autoreactive $B$ cells was abrogated in the absence of $\mathrm{CD}^{+} \mathrm{T}$ cells, demonstrating that the survival, expansion, and activation of anti-DNA B cells is T cell dependent. Finally, we demonstrate that the immunostimulatory effects of prolactin are genetically determined, as demonstrated by the lack of response to prolactin in $\mathrm{R} 4 \mathrm{~A}-\gamma 2 \mathrm{~b} \mathrm{C} 57 \mathrm{Bl} / 6$ mice.

\section{Methods}

Transgenic mice. R4A- $\gamma 2 \mathrm{~b} \mathrm{BALB} / \mathrm{c}$ and $\mathrm{C} 57 \mathrm{Bl} / 6$ mice and CD4-deleted (knockout) R4A- $\gamma 2 \mathrm{~b}$ transgenic $\mathrm{BALB} / \mathrm{c}$ mice were bred at the animal facility of the Albert Einstein College of Medicine. The R4A- $\gamma 2 \mathrm{~b}$ $\mathrm{BALB} / \mathrm{c}$ mice have been bred to the BALB/c background for well over 20 generations. R $4 A-\gamma 2 b$ C57B1/6 mice were generated by backcrossing the $\mathrm{R} 4 \mathrm{~A}-\gamma 2 \mathrm{~b}$ transgene onto the C57B $1 / 6$ background for more than 15 generations. CD4-deficient mice have been bred onto a BALB/c background for 10 generations before interbreeding with $R 4 A \gamma 2 b$ $\mathrm{BALB} / \mathrm{c}$ mice. Ovariectomized female mice (8-16 weeks of age) were used in these studies.

Prolactin treatment. The R $4 \mathrm{~A}-\gamma 2 \mathrm{~b}$ mice were injected subcutaneously with $25 \mu \mathrm{g}$ of recombinant mouse prolactin (National Hormone and Peptide Program, NIH, supplied by A. F. Parlow), $100 \mu \mathrm{g}$ of ovine prolactin (Sigma-Aldrich, St. Louis, Missouri, USA), or $100 \mu \mathrm{l}$ of saline as a placebo each day for 4 weeks. Prolactin levels in placebo- and prolactin-treated mice were determined by RIA by the National Hormone and Peptide Program at Harbor-UCLA Medical center (Torrance, California, USA).

ELISAs. Immulon-2 plates (Dynex Technologies, Chantilly, Virginia, USA) were coated with calf thymus dsDNA as described. Culture supernatants normalized to $5 \mu \mathrm{g} / \mathrm{ml} \mathrm{IgG2b}$ or serum at various dilutions were assayed for anti-dsDNA antibodies.

Flow cytometry. Splenocytes were isolated from prolactin- and placebo-treated mice. After red blood cell lysis, cells were stained with FITC-, phycoerythrin-, Cy-, or allophycoerythrin-conjugated antibodies specific for CD19, $\gamma 2 b$, CD22, VCAM-1, SHP-1, Bcl-2, CD40, B 7.1 and B 7.2, CD21, CD23, and CD24 (HSA; PharMingen, San Diego, California, USA) at $4^{\circ} \mathrm{C}$ for 30 minutes; the cells were then washed, fixed with $2 \%$ paraformaldehyde, and analyzed by flow cytometry (Becton Dickinson, Mountain View, California, USA). For intracellular staining of Bcl-2 and SHP-1, cells were permeabilized with $0.3 \%$ saponin.

ELISpot assay. Splenocytes pooled from prolactin- and placebo-treated mice were labeled with anti-CD21 FITC and anti-CD23 phycoerythrin. Marginal zone (CD21 $1^{\text {high }} / \mathrm{CD} 23^{\text {low }}$ ) and follicular (CD2 $1^{\text {intermediate }}$ CD23 $\left.{ }^{\text {low }}\right) \mathrm{B}$ cells isolated with a FACSVantage cell sorter (Becton Dickinson) were added in serial dilution to DNA-coated plates and incubated for 6 hours at $37^{\circ} \mathrm{C}$. Biotin-conjugated goat anti-mouse $\gamma 2 \mathrm{~b}$ (Southern Biotechnology, Birmingham, Alabama, USA) diluted 1:500 was added, followed by alkaline phosphataseconjugated streptavidin (Southern Biotechnology) at a 1:1000 dilution. The plates were developed with 5-bromo-4-chloro-3 indolyl phosphate substrate (Sigma-Aldrich). DNA-reactive spots were counted under a dissecting microscope.

Immunohistochemistry. Kidney sections were prepared as previously described (51). Formalin-fixed, paraffin-embedded kidney sections were stained with 


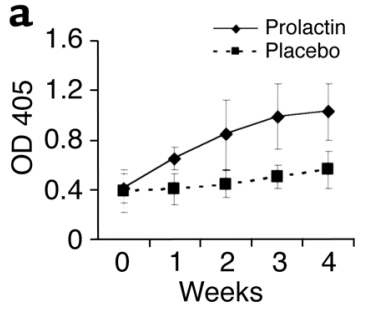

b

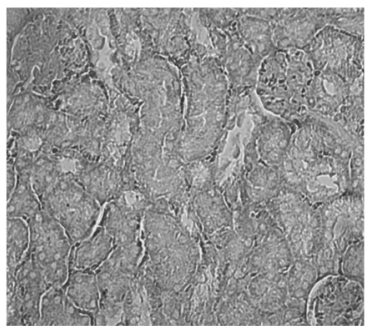

Placebo
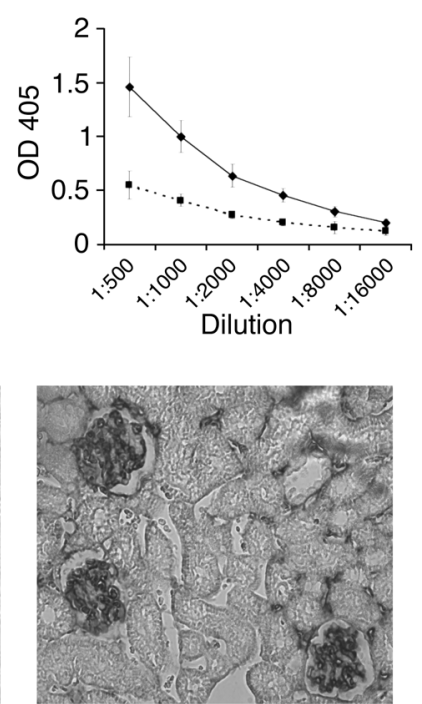

Prolactin

biotinylated anti-mouse $\operatorname{IgG}$ antibody and developed with the alkaline phosphatase $\mathrm{ABC}$ detection kit (Vector Laboratories, Burlington, California, USA).

Five-micrometer-thick frozen spleen sections from prolactin- or placebo-treated R4A- $\gamma 2 \mathrm{~b}$ BALB/c mice were fixed in acetone for 5 minutes, blocked with $3 \%$ BSA/PBS for 30 minutes, and incubated for 30 minutes with a 1:200 dilution of 7-amino-4 methylcoumarin-3acetic acid-labeled anti-IgM (Jackson Immuno Research Laboratories, West Grove, Pennsylvania, USA) and Texas red-labeled anti- $\gamma 2 \mathrm{~b}$ (PharMingen).

$B$ cell bybridomas. Splenocytes were isolated from R $4 A-\gamma 2 b$ BALB/c mice after 4 weeks of treatment with ovine prolactin. Red blood cells were lysed, and isolated splenocytes were fused with NSO cells at a $2: 1$ ratio as previously described (52). Cells from positive wells were cloned, and their DNA reactivity was determined by DNA ELISA.

The anti-dsDNA antibody-producing hybridomas were screened for transgene expression by RNA dot blot using a ${ }^{32}$ P-labeled 210-bp DNA fragment that detects all members of the $\mathrm{S} 107 \mathrm{~V}_{\mathrm{H}}$ family (47). The S107 $\mathrm{V}_{\mathrm{H}}$-positive hybridomas were screened for

\section{Figure 2}

Analysis of peripheral B cell lymphocytes. Splenocytes were isolated from seven murine prolactin-treated and seven placebo-treated mice after 4 weeks of treatment. (a) A higher percentage of B cells express $\gamma 2 b$ in prolactin-treated than in placebo-treated mice $(P=0.01)$. The total number of $\gamma 2 \mathrm{~b}$ cells in the spleens of prolactintreated mice was $3.98 \pm 0.84 \times 10^{6}$, as compared with $2.3 \pm 0.53$ $\times 10^{6}$ in placebo-treated mice. (b) $\gamma 2 \mathrm{~b}$ staining of splenocytes Representative dot plot showing an increased number of $\gamma 2 b$-expressing cells in prolactin-treated mice. (c) Localization of IgG2bexpressing B cells. B cell regions in the spleen were identified with anti-IgM staining (blue); $\gamma 2$ b-expressing $B$ cells were labeled with anti- $\gamma 2 \mathrm{~b}$ (yellow). The spleens of prolactin-treated mice displayed an expansion of the $\gamma 2 b B$ cells, which were found mainly in the follicles. In spleens of placebo-treated mice, transgene-bearing $B$ cells were localized to the $T / B$ cell interface.

\section{Figure 1}

(a) Serum titers of anti-dsDNA antibodies. Fourteen R4A- $\gamma 2 b$ $\mathrm{BALB} / \mathrm{c}$ mice were injected subcutaneously with $100 \mu \mathrm{g}$ of murine prolactin daily and 12 were injected with placebo daily for 4 weeks. Sera collected before initiation of treatment and weekly thereafter showed an increase in anti-DNA titer in placebo-treated mice. AntiDNA reactivity assayed from serum obtained at the end of the treatment showed that prolactin-treated mice had significantly higher titers of anti-DNA antibody than placebo-treated mice $(P=0.023)$. OD 405, optical density at 405 nanometers. (b) Immunohistochemistry of kidney sections. Fourteen prolactin-treated and 12 placebo-treated R4A- $\gamma 2$ b BALB/c mice were sacrificed after 4 weeks of treatment. The kidneys were stained for IgG deposition. Anti-DNA deposits were found in prolactin-treated mice but not in placebotreated mice. Representative sections from mice treated with prolactin or placebo are shown. Magnification, $\times 40$.

expression of a VK1 light chain by RNA dot blot using a 230-bp probe for genes of the VК1 family (48).

Vк1 light chains of anti-dsDNA-secreting hybridomas were sequenced. RNA was extracted, and RT-PCR was performed using a VK1 FR1 primer and a $\kappa$ constant region primer as described (48). The PCR products were purified with the use of the Qiaquick purification kit (Qiagen Inc., Santa Clara, California, USA). $\mathrm{V}$ gene sequences were determined using an ABI 377 automated sequencer (Perkin Elmer, Applied Biosystems Division, Foster City, California, USA). Sequence

$\mathbf{a}$

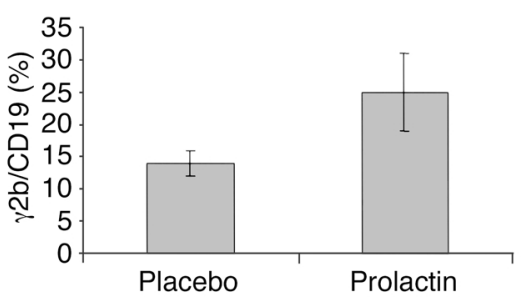

b

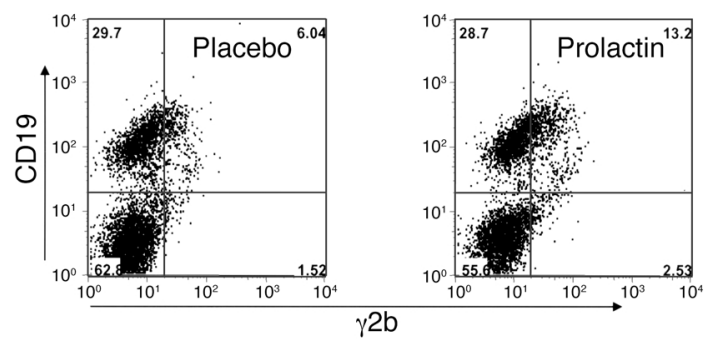

C

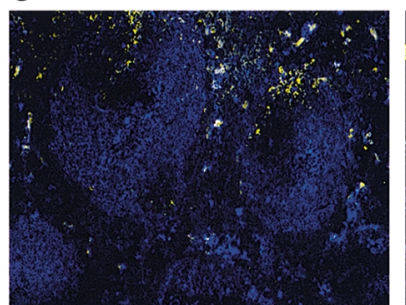

Placebo

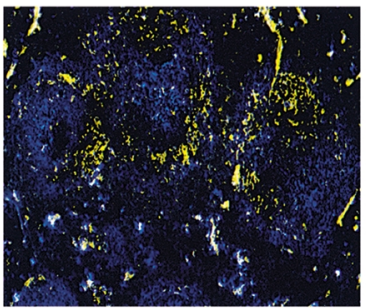

Prolactin 
a

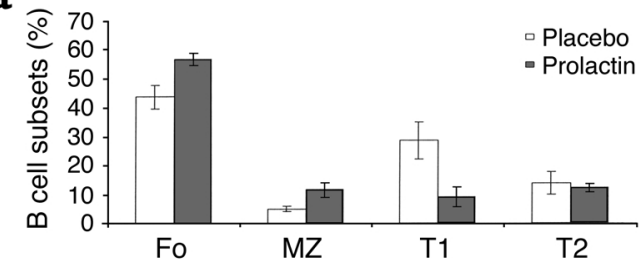

b

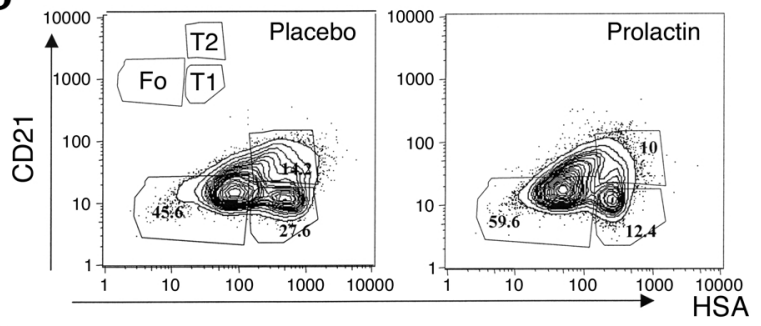

C
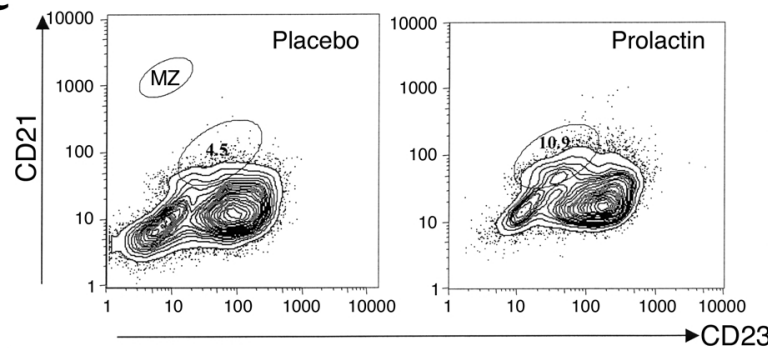

d

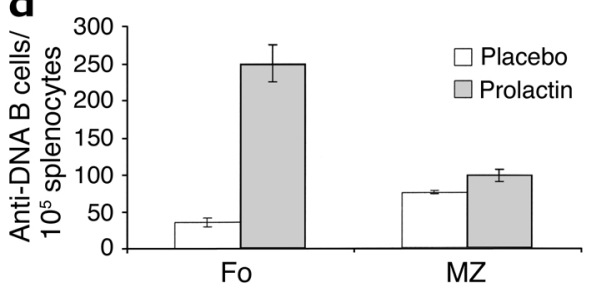

analysis was performed with Genetics Comparison Group Software (Madison, Wisconsin, USA).

Statistical Analysis. Standard statistical tests (mean value, standard deviation, two-tailed Student's $t$ test) were performed for data analysis.

\section{Results}

Anti-dsDNA antibody production in prolactin- and placebotreated mice. We have previously demonstrated that estrogen can rescue a high-affinity DNA-reactive $B$ cell population that is normally deleted in the R4A- $\gamma 2$ b BALB/c mouse (53). We have also demonstrated that increased anti-dsDNA titers in estrogentreated mice can be abrogated by bromocriptine, thereby demonstrating that some of the immunostimulatory effects of estrogen require that prolactin be present (3). In order to determine whether prolactin itself can abrogate $B$ cell tolerance, we analyzed anti-dsDNA serum titers in R4A- $\gamma 2 \mathrm{~b}$ mice treated with murine prolactin. Fourteen female R $4 A-\gamma 2 b$ $\mathrm{BALB} / \mathrm{c}$ mice were treated daily with prolactin, and 12 were treated with saline. Serum samples were collected on a weekly basis starting a day before initiation of treatment and analyzed for anti-dsDNA

\section{Figure 3}

B cell maturation. (a) Splenocytes from nontransgenic BALB/c mice treated with murine prolactin $(n=5)$ or placebo $(n=3)$ were stained for CD19, CD21, CD23, and HSA and were analyzed for T1, T2, marginal zone, and follicular subsets. B cell subsets were analyzed on the basis of data obtained with CD21 and HSA staining for the T1, T2, and follicular subsets and CD21 and CD23 staining for the marginal zone subset. (b) In prolactin-treated mice, the numbers of immature HSA ${ }^{\text {high }}$ transitional $\mathrm{B}$ cells were reduced $(P=0.002)$. In the mature $\mathrm{HSA}^{\text {low }} \mathrm{B}$ cell population, the numbers of follicular (CD21 intermed/HSAlow) B cells were increased $(P=0.002)$. (c) The marginal zone $B$ cell subset $\left(C D 21^{\text {high }} / C D 23^{\text {low }}\right)$ was increased in prolactin-treated mice $(P=0.005)(\mathbf{d})$ ELISpot assay of follicular and marginal zone $B$ cells pooled from four ovine prolactin-treated or four placebo-treated mice demonstrated an increase in the number of spontaneously secreting DNA-reactive follicular B cells. MZ, marginal zone; Fo, follicula.

reactivity by ELISA. Prolactin levels were $68.3 \pm 20.75$ nanograms $/ \mathrm{ml}(\mathrm{ng} / \mathrm{ml})$ in prolactin-treated mice and $30.3 \pm 19.7 \mathrm{ng} / \mathrm{ml}$ in placebo-treated mice, demonstrating that prolactin administration caused a twofold increase in serum concentration. By the fourth week of treatment, the titers of $\operatorname{IgG} 2 \mathrm{~b}$ antidsDNA antibodies increased significantly in prolactin-treated R4A- $\gamma 2 \mathrm{~b}$ BALB/c mice (Figure 1a). There was no detectable IgM anti-DNA reactivity or IgG 1 anti-DNA reactivity.

Glomerular IgG deposition was detected in the kidneys of 11 of 14 prolactin-treated R4A- $\gamma 2 \mathrm{~b}$ mice, suggesting that increased levels of prolactin led to secretion of potentially nephritogenic, high-affinity anti-dsDNA antibodies. Only 2 of 12 placebo-treated mice had any glomerular IgG, and these glomeruli were minimally affected (Figure 1b). These findings are consistent with the previous observation that unmanipulated R4A- $\gamma 2 \mathrm{~b}$ mice effectively regulate the production of anti-dsDNA antibodies (46). The increase in anti-dsDNA antibody titer and the associated glomerular immunoglobulin deposition observed
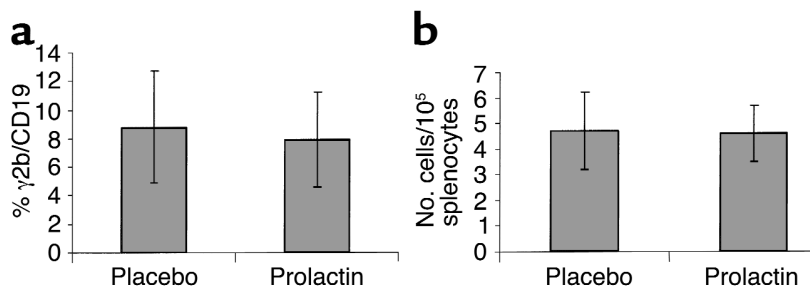

\section{Figure 4}

Anti-DNA B cells in CD4 knockout R4A- $\gamma 2$ b transgenic BALB/c mice. Splenocytes were isolated from seven murine prolactin-treated and seven placebo-treated CD4 knockout R4A- $\gamma 2 b$ BALB/c mice after 4 weeks of treatment and were evaluated for $\gamma 2 b$ expression and the number of spontaneously activated DNA-reactive B cells. (a) Prolactin- and placebo-treated mice displayed the same difference in the percentage of $B$ cells expressing $\gamma 2 b$. The total numbers of $\gamma 2 \mathrm{~b}$ cells in the spleens of prolactin- and placebo-treated mice were $1.82 \pm 0.76 \times 10^{6}$ and $1.67 \pm 0.51 \times 10^{6}$, respectively. (b) ELISpot assay showed that prolactin did not induce an increase in the number of anti-DNA antibody-secreting B cells (cells). 

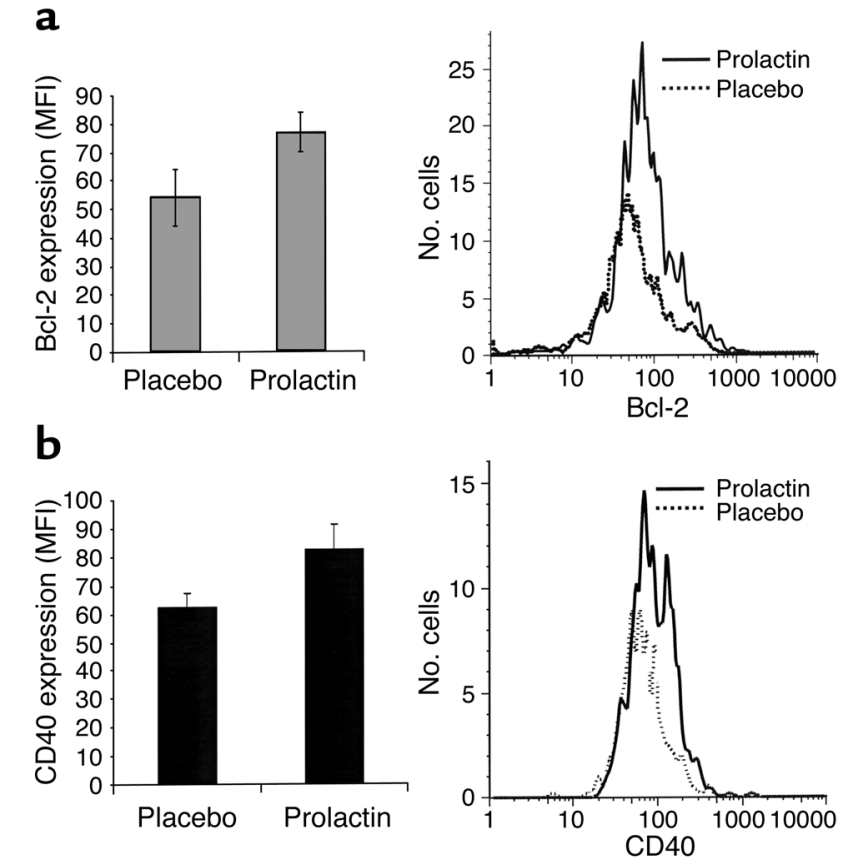

in prolactin-treated $\mathrm{R} 4 \mathrm{~A}-\gamma 2 \mathrm{~b} \mathrm{BALB} / \mathrm{c}$ mice demonstrate that prolactin can break tolerance sufficiently to produce a disease-related phenotype.

Peripheral $B$ cell analysis. In the R $4 \mathrm{~A}-\gamma 2 \mathrm{~b}$ mouse, essentially all $\gamma 2 \mathrm{~b} B$ cells express the transgene (48, 49). An expansion of the transgene-expressing $B$ cell population was observed in $\mathrm{R} 4 \mathrm{~A}-\gamma 2 \mathrm{~b} \mathrm{BALB} / \mathrm{c}$ mice after prolactin treatment (Figure 2, $\mathrm{a}$ and $\mathrm{b}$ ). Increased survival of transgene-expressing $B$ cells was also confirmed by immunohistochemistry of splenic sections, with the transgene-expressing B cells localized mainly to the follicles (Figure 2c).

To investigate effects of prolactin on $B$ cell development, we analyzed B cell subsets in prolactin-treated mice. To avoid any artifact introduced by the presence of the transgene, we analyzed nontransgenic BALB/c mice. Murine prolactin induced an expansion of mature B cells and a decrease in transitional B cells, mainly due to a decrease in the transitional type 1 (T1) $\mathrm{B}$ cells (CD21 1ow/HSA high) (Figure 3 , a and $b$ ). Of note, in placebo-treated mice the percent of transitional type

\section{Figure 6}

Prolactin effects on $B$ cells are genetically determined. Ten murine prolactin-treated and 10 placebo-treated $\mathrm{R} 4 \mathrm{~A}-\gamma 2 \mathrm{~b} \mathrm{C} 57 \mathrm{Bl} / 6$ mice were evaluated for serum anti-DNA reactivity, glomerular IgG deposits, and anti-DNA-secreting B cells. (a) There was no difference in the serum anti-DNA reactivity between prolactin- and placebo-treated mice. (b) Transgene-expressing B cells were equal in both prolactin- and placebo-treated mice. The total number of splenic B cells expressing $\gamma 2 b$ was $2.12 \pm 0.63 \times 10^{6}$ in placebotreated mice, as compared with $2.23 \pm 0.55 \times 10^{6}$ in prolactintreated mice.(c) Prolactin-treated mice did not exhibit a higher number of B cells spontaneously secreting anti-DNA antibody or an increased responsiveness to anti-CD40 antibody and IL-4. Cells, anti-DNA antibody-secreting cells.

\section{Figure 5}

Gene expression. B cells from ovine prolactin- and placebo-treated mice were analyzed for cell surface and intracellular markers. (a) $\mathrm{Bcl}-2$ expression was increased in $\mathrm{B}$ cells of prolactin-treated mice $(P=0.003)$. (b) CD40 expression was increased in B cells of prolactin-treated mice. $(P=0.008)$. MFI, mean fluorescence intensity.

2 (T2) B cells (CD21 high $\left./ \mathrm{HSA}^{\text {high }}\right)$ is lower than the percent of $\mathrm{T} 1$ cells; in prolactin-treated mice, there was no decrease in the percent of $\mathrm{T} 2$ cells as compared with the percent of $\mathrm{T} 1$ cells (Figure 3 , a and b). These observations suggest that prolactin may decrease negative selection of immature B cells, which has been reported to occur within the transitional B cell population as T1 cells mature to T2 cells (54). Furthermore, prolactin induced an increase in both marginal zone $\left(\mathrm{CD} 21^{\text {high }} / \mathrm{CD} 23^{\text {low }}\right)$ (Figure $3 \mathrm{c}$ ) and follicular (CD2 $1^{\text {intermediate }} / \mathrm{HSA}^{\text {low }}$ or $\left.\mathrm{CD} 2^{\text {intermediate }} / \mathrm{CD} 23^{\text {high }}\right) \mathrm{B}$ cells (Figure 3, b and c, respectively). Ovine prolactin induced the same alteration in $\mathrm{B}$ cell subsets as murine prolactin (data not shown).

To identify which B cell subset was responsible for anti-DNA antibody production, we isolated follicular and marginal zone $B$ cells from four placebo-treated mice and four R4A- $\gamma 2 \mathrm{~b}$ BALB/c mice treated with ovine prolactin and enumerated spontaneously secreting anti-DNA B cells by ELISpot assay. There was a small increase in the number of IgG2b-producing anti-DNA antibody-secreting marginal zone $\mathrm{B}$ cells in prolactintreated mice; however, there was a greatly expanded number of anti-dsDNA antibody-secreting cells in the follicular B cell population (Figure 3d).

Cellular and genetic studies of autoreactive B cells. To evaluate whether both the survival and the activation of autoreactive $B$ cells observed in prolactin-treated mice requires the presence of $T$ cells, we investigated the effect of prolactin on treatment of R $4 A-\gamma 2 b$ BALB/c mice deficient in $\mathrm{CD} 4^{+} \mathrm{T}$ cells (CD4 knockout mice). In the absence of $\mathrm{CD}^{+} \mathrm{T}$ cells, prolactin did not lead to increased serum titers of anti-DNA antibody (data
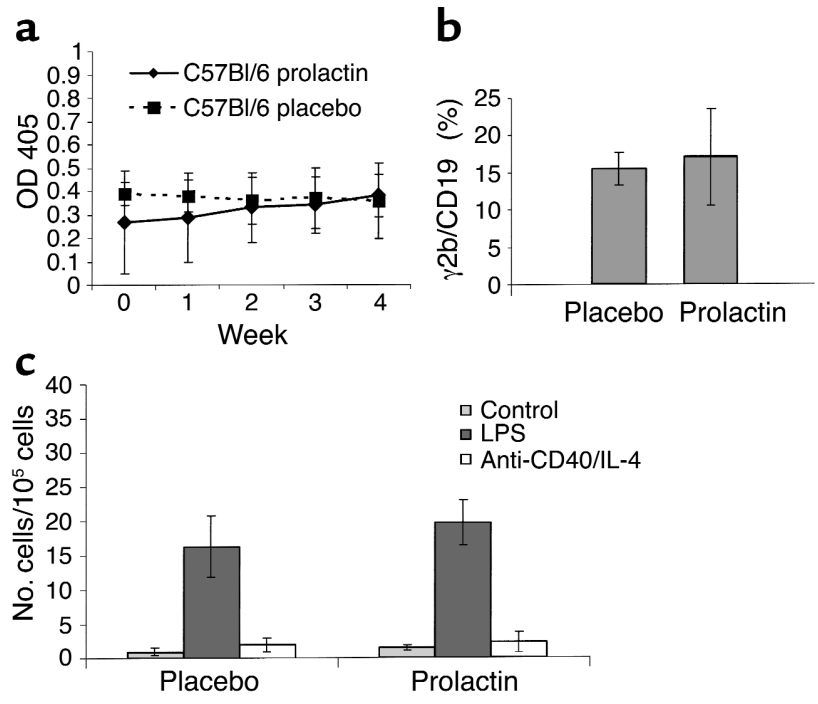
Table 1

VK usage in DNA-reactive hybridomas

\begin{tabular}{|c|c|c|}
\hline Clone & Vк gene & $\mathrm{J} \kappa$ gene \\
\hline 31-C11 & $\mathrm{VK} 1 \mathrm{~A}$ & $\mathrm{~J} \kappa 2$ \\
\hline 83-E4 & $\mathrm{V} \kappa 1 \mathrm{~A}$ & Јк2 \\
\hline $32-F 2$ & Vк $1 \mathrm{~A}$ & Јк2 \\
\hline C3-E7 & $\mathrm{V \kappa} 1 \mathrm{~A}$ & Јк1 \\
\hline $\mathrm{C} 8-\mathrm{C} 4$ & Vк 8-24 & ЈК1 \\
\hline $58-C 5$ & Vк $1 \mathrm{~A} 5$ & Јк2 \\
\hline $34-2$ & Vк $1 \mathrm{~A}$ & ЈК1 \\
\hline $38-1$ & Vк $24 \mathrm{C}$ & Јк2 \\
\hline $81-1$ & $\mathrm{~V} \kappa 1 \mathrm{~A}$ & JК4 \\
\hline
\end{tabular}

not shown). There was no expansion of the transgeneexpressing population (Figure 4a), nor was there an increased number of spontaneously activated DNAreactive $B$ cells (Figure $4 \mathrm{~b}$ ). Thus, the effect of prolactin on both survival and activation of autoreactive $B$ cells requires $\mathrm{CD}^{+} \mathrm{T}$ cells.

Prolactin-treated mice displayed an expansion of transgene-expressing $\mathrm{B}$ cells and a shift in the T1/T2 ratio similar to that which we have previously reported in estrogen-treated R4A- $\gamma 2 \mathrm{~b}$ mice. To understand the molecular basis for these changes, we investigated the B cells from R4A- $\gamma 2 b$ transgenic BALB/c mice for the expression of molecules important in the survival and activation of $B$ cells that are known to be upregulated by estrogen, such as Bcl-2 (53), CD22, VCAM-1, and SHP-1 (55). Bcl-2 was upregulated by prolactin (Figure 5a), but no significant increase in the expression of the other molecules was observed in prolactin-treated mice (data not shown).

Because $T$ cells were required for a prolactin-induced breakdown in B cell tolerance, we analyzed expression of the costimulatory molecules B7.1/B7.2 and CD40 on $B$ cells after prolactin treatment. Prolactin increased the expression of CD40 on B cells (Figure 6) but did not significantly affect the expression of B7.1 or B7.2 (data not shown).

$B$ cell bybridomas from prolactin-treated mice. We have previously reported the inability to obtain high-affinity anti-DNA hybridomas from unstimulated splenocytes of placebo-treated mice. In fact, eight fusions of spleen cells from untreated or placebo-treated mice yielded no high-affinity anti-DNA hybridomas. To characterize the DNA-reactive $B$ cells present in mice treated with ovine prolactin, we performed fusions of unstimulated splenic B cells. Approximately 500 wells from two fusions were screened, and 42 DNAreactive hybridomas were obtained. Thirty-eight lines were tested for transgene expression, and all were positive. Twenty-six hybridomas were cloned; 14 produced high-affinity anti-dsDNA antibody. Thus, approximately $3 \%$ of the hybridomas were making high-affinity anti-DNA antibodies. Of the nine evaluated for light-chain gene usage, six were found to

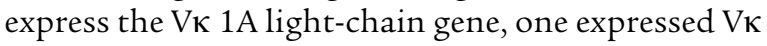

1A5, one Vк 8-24, and one Vк 24C (GenBank accession numbers: AJ23201, AJ235944, AJ231205, and AJ231263) (Table 1). Four of the light chains were unmutated (31-C11, 32-F2, 34-2, and 38-1). The other five light-chain genes displayed one or two replacement mutations. Studies of anti-DNA antibodies derived from these mice clearly demonstrate that four of the light chains (83-E4, C8-C4, 34-2, and 81-1) encoded high-affinity anti-DNA antibodies in their germline configuration. Whether the mutation in 58-C5 led to high-affinity reactivity with DNA is not known. These data demonstrate that prolactin rescued high-affinity autoreactive $B$ cells, which are part of the naive repertoire that normally undergoes deletion. Prolactin also may rescue mature, somatically mutated B cells from anergy, but there is not sufficient evidence to determine this.

Immunological effects of prolactin are genetically determined. To determine whether the effects of prolactin in breaking tolerance in BALB/c mice are genetically restricted, we evaluated the impact of prolonged treatment with prolactin on $B$ cells in mice with a different genetic background. We treated R $4 \mathrm{~A}-\gamma 2 \mathrm{~b}$ C57Bl/6 mice with the same dose regimen of murine prolactin as R $4 A-\gamma 2 b$ BALB/c mice. These mice were generated by mating the R4A- $\gamma 2 \mathrm{~b}$ transgene onto the C57B1/ 6 background for more than 15 generations. Thus, the copy number and insertional site of the transgene is the same as in BALB/c mice. Prolactin-treated R4A- $\gamma 2 \mathrm{~b}$ $\mathrm{C} 57 \mathrm{Bl} / 6$ mice did not develop anti-DNA titers. There was no expansion of transgene-expressing $B$ cells and no increase in the number of B cells spontaneously secreting anti-DNA antibody (Figure 6, a-c).

\section{Discussion}

Clinical data and studies in animal models have implicated prolactin as a possible exacerbating factor in SLE. A significant number of patients with lupus have increased serum prolactin levels (29-31), and increased spontaneous secretion of prolactin has been demonstrated by peripheral-blood mononuclear cells of patients with lupus $(41,42)$. Hyperprolactinemia in lupus-prone mice accelerates disease activity and mortality $(4,5)$. Over the past several years, it has been appreciated that prolactin is an important component of neuroendocrine and immune interactions and functions as a regulator of the immune response, but its mechanisms of action at the cellular and molecular level have not been fully described.

We chose to study the effect of prolactin on the $\mathrm{R} 4 \mathrm{~A}-\gamma 2 \mathrm{~b}$ mouse. This mouse is well characterized and offers an opportunity to study survival and activation of different populations of autoreactive B cells. Using this model, we demonstrate that on a BALB/c genetic background, a twofold increase in serum prolactin breaks tolerance and induces a lupus-like illness. This increase is similar to that seen in patients with SLE and hyperprolactinemic mice. In R4A- $\gamma 2 \mathrm{~b}$ BALB/c mice, treatment with prolactin induced an 
increased number of transgene-expressing B cells, with a resulting rise in serum anti-DNA titers and IgG deposits in the glomeruli. The anti-DNA B cell population present in prolactin-treated mice displayed a follicular B cell phenotype, and the expansion of transgene-expressing B cells was evident in the follicles. Hybridomas secreting high-affinity DNA-binding antibodies expressed germline VK $1 \mathrm{~A}$ light-chain genes. These observations demonstrate that prolactin rescues high-affinity autoreactive $B$ cells, which are part of the naive repertoire that normally undergo deletion.

We demonstrate in nontransgenic mice that prolactin alters $B$ cell development and maturation, causing an expansion of the number of $\mathrm{B}$ cells with a mature phenotype and a decrease in the number of transitional B cells. In prolactin-treated, mice there is no decrease in the number of T2 B cells as compared with T1 B cells. Since it has been demonstrated that negative selection occurs at the $\mathrm{T} 1$ to $\mathrm{T} 2$ transition, this observation is consistent with a lack of negative selection of immature B cells (56). Prolactin treatment leads to an increase in both follicular and marginal zone $B$ cell subsets, but the majority of autoreactive $\mathrm{B}$ cells develop as follicular B cells.

There are studies implicating both marginal zone and follicular B cells in the production of anti-DNA antibodies in murine lupus. Understanding which subset is critical for autoantibody production has potential therapeutic value. As each subset displays different requirements for activation, different interventions might be need to block activation. Prolactin exerts its main autoimmune effects on the $\mathrm{T}$ cell-dependent follicular $B$ cell subset. There was an absence of an autoimmune phenotype in prolactin-treated $\mathrm{BALB} / \mathrm{c}$ mice that are deficient in $\mathrm{CD}^{+} \mathrm{T}$ cells. This is consistent with previous studies showing that $\mathrm{T}$ cells are required for the maintenance of the follicular B cell population (57). Thus, in the absence of $\mathrm{CD}^{+} \mathrm{T}$ cells, there is no mature population of anti-DNA B cells in prolactin-treated mice. Although treatment with prolactin also induces an expansion of the $\mathrm{T}$-independent marginal zone $\mathrm{B}$ cell population, the contribution of this population to the prolactin-induced breakdown of tolerance is small.

Some recent studies suggest that marginal zone B cells develop when B cell receptor signaling is low, whereas follicular B cells develop under conditions of stronger $B$ cell receptor signaling. Molecules that affect the strength of $\mathrm{B}$ cell receptor signaling such as Aiolos, Btk, and CD21 all alter B cell development, with a decrease in Aiolos or an increase in Btk or CD21 leading to the development of follicular cells (58). It has also been shown that Notch-RBP-J and Pyk-2 expression are critical for marginal zone $\mathrm{B}$ cell development, demonstrating that $\mathrm{B}$ cell receptor (BCR) signaling alone does not determine $B$ cell fate (59).

Why prolactin causes autoreactive $\mathrm{B}$ cells to mature as follicular cells is not known; however, some of the changes we detect in gene expression may help explain the prolactin-induced altered B cell repertoire and the activation of autoreactive follicular $\mathrm{B}$ cells. Bcl-2 has been shown to enhance survival of immature autoreactive $B$ cells in the bone marrow and to permit their transit to peripheral lymphoid organs (60). Prolactin has been reported to suppress apoptosis in hematopoietic cells and in cells in mammary and prostate glands, and recent studies in the $\mathrm{Nb} 2 \mathrm{~T}$ cell line have shown that prolactin increases survival by stimulating the rapid expression of several antiapoptotic genes, including bcl-2 (61). Our data demonstrate that prolactin can enhance Bcl-2 expression in B cells. This increase in Bc1-2 is likely to contribute to a decrease in negative selection or apoptosis of autoreactive $B$ cells.

Prolactin has been shown to increase antigen presentation by dendritic cells (62). This observation has led to the speculation that prolactin might increase expression of CD40 (62). Here, we demonstrate that prolactin leads to increased expression of CD 40 on $B$ cells. It has previously been demonstrated that CD40 engagement can rescue transitional B cells from BCR-mediated apoptosis (63). We speculate that this rescue pathway is functional to permit autoreactive cells in prolactin-treated mice to reach maturity. It is interesting to note that CD40L expression has been demonstrated on B cells of patients with SLE (64), suggesting that enhanced costimulation is present. Furthermore, the finding that prolactin leads to increased CD40 expression is consistent with the requirement for $\mathrm{T}$ cells to be present for prolactin to modulate $B$ cell selection and maturation. Because prolactin-induced survival and activation of antiDNA B cells requires $\mathrm{CD}^{+} \mathrm{T}$ cells, costimulatory blockade may be a useful therapeutic tool for treatment of the prolactin-responsive subgroup of patients with lupus.

Although both estrogen and prolactin abrogate tolerance in R4A- $\gamma 2 \mathrm{~b} B A L B / c$ mice, they lead to autoreactivity in different $B$ cell subsets. This observation shows that estrogen does not exert its effect on the immune response by upregulation of prolactin. Prolactin-treated mice display autoreactive follicular B cells, whereas estrogen-treated mice display autoreactive marginal zone B cells. Differential features of gene expression help explain this difference. Several molecules that are implicated in B cell survival and activation that are elevated in estrogen-treated mice, such as CD22, VCAM-1, and SHP-1 (55), are not increased in $\mathrm{B}$ cells of prolactin-treated mice. It is reasonable to speculate that the increase in CD22 and SHP-1 induced by estrogen contributes to the greatly enhanced maturation of marginal zone B cells. Increased CD22 and SHP-1 would lead to reduced $\mathrm{BCR}$ signaling and the preferential development of a marginal zone phenotype. With the greater B cell receptor signaling that would occur with normal levels of CD22 and SHP-1, the follicular B cell phenotype would predominate. It is interesting to note that the 
same anti-DNA B cells develop as follicular B cells in prolactin-treated mice and as marginal zone $B$ cells in estrogen-treated mice (51). This observation confirms the observations of others that antigenic specificity alone does not determine the developmental pathway of a B cell $(58,59,65,66)$.

The same prolactin treatment that induced a lupuslike phenotype in $\mathrm{R} 4 \mathrm{~A}-\gamma 2 \mathrm{~b} \mathrm{BALB} / \mathrm{c}$ mice did not break tolerance in $\mathrm{R} 4 \mathrm{~A}-\gamma 2 \mathrm{~b} \mathrm{C} 57 \mathrm{Bl} / 6$ mice, demonstrating the importance of the genetic background in determining the response to hormonal influences. Studies of animal models of SLE have identified more than 30 chromosomal regions containing genes that affect lupus susceptibility (67). Several of these loci map to overlapping regions of chromosomes 1 , $5,7,11,18$, and 19 (68) and to the MHC locus on chromosome 17, but the majority of the detected loci are strain specific (69). The finding that prolactin can break tolerance and induce a lupus-like serology supports the hypothesis that sex hormones are involved in the regulation of autoimmunity. The strain specificity of this response suggests that some strains have lupus suppressor genes that counter the effect of hormones or, alternatively, that those strains require more hormone to induce disease. In patients in whom antibodies are produced by follicular B cells, interfering with prolactin-responsive pathways may attenuate disease phenotype.

\section{Acknowledgments}

The authors would like to thank M. Sharff for critical reading of the manuscript, $S$. Jones for preparation of the manuscript, and E. Kloszewski for assistance with flow cytometry. This work was supported by grants from the NIH.

1. Lahita, R.G. 1999. The role of sex hormones in systemic lupus erythematosus. Curr. Opin. Rheumatol. 11:352-356.

2. McMurray, R.W. 2001. Estrogen, prolactin, and autoimmunity: actions and interactions. Int. Immunopharmacol. 6:995-1008.

3. Elbourne, K.B., Keisler, D., and McMurray, R.W. 1998. Differential effects of estrogen and prolactin on autoimmune disease in the NZB/NZW F1 mouse model of SLE. Lupus. 7:420-427.

4. Peeva, E., Grimaldi, C., Spatz, L., and Diamond, B. 2000. Bromocriptine restores tolerance in estrogen-treated mice. J. Clin. Invest. 106:1373-1379.

5. McMurray, R., Keisler, D., Izui, S., and Walker, S. 1994. Hyperprolactinemia in male NZB/NZW (B/W) F1 mice: accelerated autoimmune disease with normal circulating testosterone. Clin. Immunol. Immunopathol. 71:338-343.

6. McMurray, R., Keisler, D., Kanuckel, K., Izui, S., and Walker, S. 1991. Prolactin influences autoimmune disease activity in the female NZB/W mouse. J. Immunol. 147:3780-3787.

7. Neidhart, M. 1997. Bromocriptine has little direct effect on murine lymphocytes, the immunomodulatory effect being mediated by the suppression of prolactin secretion. Biomed. Pharmcother. 51:118-125.

8. Ben-Jonathan, N., Mershon, J.L., Allen, D.L., and Stenmetz, R.M. 1996 Extrapituitary prolactin: distribution, regulation, functions, and clinical aspects. Endocr. Rev. 17:639-669.

9. Hiestand, P.C., Mekler, P., Nordmann, R., Grieder, A., and Permmmongkol, C. 1986. Prolactin as a modulator of lymphocyte responsiveness provides a possible mechanism of action for prolactin. Proc. Natl. Acad. Sci. USA. 83:2599-2603.

10. Hatfill, S.J., Kirby, R., Hanley, M., Rybicki, E., and Bohm, L. 1990. Hyperprolactinemia in acute myeloid leukemia and indication of ectopic expression of human prolactin in blast cells of a patient of subtype M4. Leuk. Res. 14:57-62.

11. Matera, L., Muccioli, G., Cesano, A., Bellussi, G., and Genazzani, V. 1988.
Prolactin receptors on large granular lymphocytes: dual regulation by cyclosporin A. Brain. Behav. Immun. 2:1-10.

12. Pellegrini, I., Lebrun, J., Ali, S., and Kelly, P.A. 1992. Expression of prolactin and its receptor in human lymphoid cells. Mol. Endocrinol. 6:1023-1031

13. Matera, L., et al. 1997. Prolactin as an autocrine growth factor for the Jurkat human T leukemic cell line. J. Neuroimmunol. 79:12-21.

14. Gagnerault, M.C., Touraine, P., Savino, W., Kelly, P.A., and Dardenne, M. 1993. Expression of prolactin receptors in murine lymphoid cells in normal and autoimmune situations. J. Immunol. 150:5673-5681.

15. Russel, D.H., et al. 1984. Prolactin receptors on human lymphocytes and their regulation by cyclosporine. Biochem. Biophys. Res. Commun. 121:899-906

16. Matera, L., et al. 2000. Expression of prolactin and prolactin receptors by non-Hodgkin's lymphoma cells. Int. J. Cancer. 85:124-130.

17. Montgomery, D.W., et al. 1992. Human thymocytes express a prolactin-like messenger ribonucleic acid and synthesize bioactive prolactin-like protein. Endocrinology. 131:3019-3026.

18. De Mello-Cuelho, V., Villa-Werde, D.M.S., Dardenne, M., and Savino, W. 1997. Pituitary hormones modulate cell-cell interactions between thymocytes and thymic epithelial cells. J. Neuroimmunol. 76:39-49.

19. Mukherjee, P., Mastro, A.M., and Hymer, W.C. 1990. Prolactin induction of interleukin-2 on rat splenic lymphocytes. Endocrinology. 26:88-94.

20. Gaufo, G.O., and Diamond, M.C. 1996. Prolactin increases CD4/CD8 cell ratio in thymus-grafted congenitally athymic nude mice. Proc. Natl. Acad. Sci. USA. 93:4165-4169.

21. Whitacer, C., Reingold, S.C., and O'Looney, P.A. 1999. A gender gap in autoimmunity. Science. 283:1277-1279.

22. Hartmann, D.P., Holaday, J.W., and Bernton, E.W. 1989. Inhibition of lymphocyte proliferation by antibodies to prolactin. FASEB J. 3:2194-2202

23. Clevenger, C.V., Sillman, A.L., Hanley-Hyde, J., and Pristowsky, M.B. 1992. Requirement for prolactin during cell cycle regulated gene expression in cloned T lymphocytes. Endocrinology. 130:3216-3222.

24. Vidaller, A., et al. 1986. T cell dysregulation in patients with hyperprolactinemia: effect of bromocriptine treatment. Clin. Immunol. Immunopathol. 38:337-343.

25. McMurray, R.W. 1996. Prolactin and systemic lupus erythematosus. Ann. Med. Intern. 147:253-258.

26. Lavalle, C.E., et al. 1993. Prolactin and gonadal hormones: a key relationship that may have clinical, monitoring and therapeutic implications in systemic lupus erythematosus. Lupus. 2:71-75.

27. Walker, S.E., et al. 1998. Effects of prolactin in stimulating disease activity in systemic lupus erythematosus. Ann. NY Acad. Sci. 840:762-772.

28. McMurray, R.W., Weidensaul, D., Allen, S.H., and Walker, S.E. 1995 Efficacy of bromocriptine in an open label therapeutic trial for SLE. J. Rheumatol. 22:2084-2091.

29. Allen, S.H., et al. 1996. Prolactin levels and antinuclear antibody profiles in women tested for connective tissue disease. Lupus. 5:30-37.

30. Jara, L.J., et al. 1992. Hyperprolactinemia in SLE: association with disease activity. Am. J. Med. Sci. 303:222-226.

31. Funauchi, M., et al. 1998. Prolactin modulates the disease activity of systemic lupus erythematosus accompanied by prolactinoma. Clin. Exp. Rheumatol. 16:479-482.

32. Mc Murray, R.W., Allen, S.H., Braun, A.L., Rodriguez, F., and Walker, S.E. 1994. Longstanding hyperprolactinemia associated with systemic lupus erythematosus: possible hormonal stimulation of an autoimmune disease. J. Rheum. 21:840-843.

33. Blackwell, R.E. 1992. Hyperprolactinemia. Evaluation and management. Endocrinol. Metab. Clin. North Am. 21:105-124.

34. Folomeev, M., et al. 1990. Prolactin levels in men with SLE and RA. J. Rheumatol. 17:1569-1570.

35. Ansar Ahmed, S., Penhale, W.J., and Talal, N. 1985. Sex hormones, immune responses, and autoimmune diseases. Am. J. Pathol. 121:531-551.

36. Neidhart, M. 1996. Elevated serum prolactin or elevated prolactin/cortisol ratios are associated with autoimmune processes in systemic lupus erythematosus and other connective tissue diseases. Br. J. Rheumatol. 23:476-481.

37. Munoz, J.A., Gil, A., Lopez-Dupla, J.M., Vazquez, J.J., and GonzalezGansedo, P. 1994. Sex hormones in chronic systemic lupus erythematosus. Correlation with clinical and biological parameters. Ann. Med. Intern. 145:459-463.

38. Ostendorf, B., et al. 1996. Hyperprolactinemia in systemic lupus erythematosus. Scand. J. Rheumatol. 25:97-102.

39. El-Garf, A., Salah, S., Shaarawy, M., Zaki, S., and Anwer, S. 1996. Prolactin hormone in juvenile systemic lupus erythematosus: a possible relationship to disease activity and CNS manifestations. J. Rheumatol. 23:374-377.

40. Miranda, J.M., et al. 1998. Clinical significance of serum and urine prolactin levels in lupus glomerulonephritis. Lupus. 7:387-391. 
41. Gutierez, M.A., et al. 1995. Prolactin and systemic lupus erythematosus: prolactin secretion by SLE lymphocytes and proliferative (autocrine) activity. Lupus. 4:348-352.

42. Larrea, F., et al. 1997. A bioactive 60-kilodalton prolactin species is preferentially secreted in cultures of mitogen-stimulated and nonstimulated peripheral blood mononuclear cells from subjects with SLE. J. Clin. Endocrinol. Metab. 82:3664-3669.

43. Stevens, A., Ray, D.W., Worthington, J., and Davis, J.R.E. 2001. Polymorphism of the human prolactin gene - implications for production of lymphocyte prolactin and SLE. Lupus. 10:676-683.

44. Alvarez-Nemegyei, J., et al. 1998. Bromocriptine in systemic lupus erythematosus: a double-blind, randomized, placebo-controlled study. Lupus. 7:414-419.

45. Mc Murray, R.W., Weidensaul, D., Allen, S.H., and Walker, S.E. 1995 Efficacy of bromocriptine in an open label therapeutic trial for systemic lupus erythematosus. J. Rheumatol. 22:2084-2091.

46. Offen, D., Spatz, L., Escowitz, H., Factor, S., and Diamond, B. 1992. Induction of tolerance to an IgG autoantibody. Proc. Natl. Acad. Sci. USA. 89:8332-8336.

47. Bynoe, M.S., Spatz, L., and Diamond, B. 1999. Characterization of anti-DNA B cells that escape negative selection. Eur. J. Immunol. 29:1304-1313.

48. Iliev, A., Spatz, L., Ray, S., and Diamond, B. 1994. Lack of allelic exclusion permits autoreactive B cells to escape deletion. J. Immunol. 153:3551-3555

49. Spatz, L., et al. 1997. Light chain usage in anti ds DNA B cell subsets: role in cell fate determination. J. Exp. Med. 185:1317-1326.

50. Kuo, P., Bynoe, M.S., Wang, C., and Diamond, B. 1999. Bcl-2 leads to expression of anti-DNA B cells but no nephritis: a model for a clinical subset. Eur. J. Immunol. 29:3168-3178.

51. Gaynor, B., et al. 1997. Peptide inhibition of glomerular deposition of an anti-DNA antibody. Proc. Natl. Acad. Sci. USA. 94:1955-1960.

52. Fazekas de St. Groth, B., and Scheidegger, D. 1980. Production of monoclonal antibodies: strategy and tactics. J. Immunol. Methods. 35:1-21.

53. Bynoe, M.S., Grimaldi, C.M., and Diamond, B. 2000. Estrogen upregulates Bcl-2 and blocks tolerance induction of naive B cells. Proc. Natl. Acad. Sci. USA. 97:2703-2708.

54. Grimaldi, C.M., Michael, D.M., and Diamond, B. 2001. Expansion and activation of a population of autoreactive marginal zone B cells in a model of estrogen induced lupus. J. Immunol. 167:1886-1890.

55. Grimaldi, C.M., Cleary, J., Dagtas, A.S., Moussai, D., and Diamond, B. 2002.
Estrogen alters thresholds for B cell apoptosis and activation. J. Clin. Invest. 109:1625-1633. doi:10.1172/JCI200214873.

56. Su, T.T., and Rawlings, D.J. 2002. Transitional B lymphocyte subsets operate as distinct checkpoints in mature splenic B cell development. J. Immunol. 168:2101-2110.

57. Hao, Z., and Rajewsky, K. 2001. Homeostasis of peripheral B cells in the absence of B cell influx from the bone marrow. J. Exp. Med. 194:1151-1164.

58. Cariappa, A., et al. 2001. The follicular versus marginal zone B lymphocyte cell fate decision is regulated by Aiolos, Btk and CD21. Immunity. 14:603-615.

59. Tanigaki, K., et al. 2002. Notch-RBP-J signaling is involved in cell fate determination of marginal zone B cells. Nat. Immunol. 5:443-450.

60. Lopez-Hoyos, M., et al. 1996. Constitutive expression of bcl-2 in B cells causes a lethal form of lupus-like autoimmune disease after induction of neonatal tolerance to H-2b alloantigens. J. Exp. Med. 183:2523-2531.

61. Buckley, A.R. 2001. Prolactin, a lymphocyte growth and survival factor. Lupus. 10:684-690.

62. Matera, L., Mori, M., and Galleto, A. 2001. Effect of prolactin on the antigen presenting function of monocyte-derived dendritic cells. Lupus. 10:728-734.

63. Sater, R.A., Sandel, P.C., and Monroe, J.G. 1998. B cell receptorinduced apoptosis in primary transitional murine B cells: signaling requirements and modulation by $\mathrm{T}$ cell help. Int. Immunol. 10:1673-1682

64. Koshy, M., Berger, D., and Crow, M.K. 1996. Increased expression of CD40 ligand on systemic lupus erythematosus lymphocytes. J. Clin. Invest. 98:826-837.

65. Samardzic, T., et al. 2002. Reduction of marginal zone B cells in CD22-deficient mice. Eur. J. Immunol. 32:561-567.

66. Guinamard, R., Okigaki, M., Schlessinger, J., and Ravetch, J.V. 2000. Absence of marginal zone B cells in Pyk-2-deficient mice defines their role in the humoral response. Nat. Immunol. 1:31-36.

67. Wakeland, E.K., Liu, K., Graham, R.R., and Behrens, T.W. 2001. Delineating the genetic basis of systemic lupus erythematosus. Immunity. 15:397-408.

68. Wandstrat, A., and Wakeland, E. 2001. The genetics of complex autoimmune disease: non-MHC susceptibility genes. Nat. Immunol. 2:802-809.

69. Hogarth, M.B., et al. 1998. Multiple lupus susceptibility loci map to chromosome 1 in BXSB mice. J. Immunol. 16:2753-2761. 